\title{
Influence of Hybrid Material Arrangements on Free Vibration Analysis of Thick FRP Skew Specially Orthotropic Laminate with Circular Cutout
}

\author{
K. Srividya ${ }^{1}$, Dr. V. Balakrishna Murthy ${ }^{2}$ and Dr. M.R.S. Satyanarayana ${ }^{3}$ \\ ${ }^{1}$ Assistant Professor, Mechanical Engineering Department, Prasad V Potluri Siddhartha \\ Institute of Technology, Vijayawada-520007, India. \\ ${ }^{2}$ Professor, Mechanical Engineering Department, Velagapudi Ramakrishna Siddhartha Engineering College, Vijayawada- \\ 520007, India. \\ ${ }^{3}$ Professor, Mechanical Engineering Department, GITAM Institute of Technology,
}

GITAM University, Visakhapatnam-530045, India.

\begin{abstract}
The present investigation deals with the influence of hybrid materials of specially orthotropic nature in free vibration analysis of a thick four-layered Fiber Reinforced Plastic skew laminated composite plate with a circular cutout. Three dimensional finite element models which use the elasticity theory for the determination of stiffness matrices are modeled in ANSYS software to evaluate first five natural frequencies of the laminate. The effect of various hybrid arrangements on the first five natural frequencies of the plate is discussed.
\end{abstract}

Keywords: Fiber reinforced plastic (FRP), finite element model (FEM), skew plate, cutout, natural frequency, free vibration.

\section{I.INTRODUCTION}

Composite materials are replacing metals in many structural applications such as aerospace, transportation, novel and pressure vessels due to their high specific strength and specific modulus. The dynamic responses of these structures differ from that made of isotropic materials due to orthotropic nature of individual layers of the laminate. Free vibration analysis is a part of dynamic analysis where the natural frequencies of the structure can be estimated. The following paragraph provides brief research contributions on free vibration analysis of FRP composite structures. The free vibrations of multi layered plates are studied by Noor [1], these results show that for composite plates the error in the predictions of the classical plate theory is strongly dependent on the number and stacking of the layers, in addition to the degree of orthotropy of the individual layers and the thickness ratio of the plate. Kant et al. [2] studied a higher order shear deformation theory with $\mathrm{C}^{\mathrm{o}}$ Finite Element formulation for vibrational analysis of unsymmetrical laminated plates. An eightnoded hybrid-stress finite element is used by Ramakrishna et al. [3] to analyse the dynamic behavior of laminated plates with cutouts. Yook-Kong Yongt et al. [4] presented the finite element formulation for an orthotropic composite plate and shell analyses by using a higher order, partial hybrid stress method. The three-dimensional theory of laminated plates and shells has been developed by Chao [5] with many applications to impact and shock modal analyses, the lowest frequencies are obtained in the present study in comparison with those in earlier studies as a result of the close natural state reached in keeping with the three-dimensional boundary and interlaminar continuity conditions via a $3-D$ augmented energy variational approach. Chun-Sheng Chen [6] studied buckling and vibration behaviors of hybrid composite plates, based on the Reissner-Mindlin plate theory. Metin Aydogdu [7] investigated the vibration analysis of angle-ply laminated beams subjected to different sets of boundary conditions based on a three-degrees-offreedom shear deformable beam theory., the Ritz method has been employed for different length to thickness ratios and hence, this method can be used effectively to study free vibration problem of generally layered composite beams with arbitrary boundary conditions. Mutasher et al. [8] investigated a static torque and power transmission capacities of a hybrid aluminium /composite drive shaft, which is fabricated by a wetted filament winding method. Isaac et al. [9] described the concepts of micro and macro mechanics of the composite materials in detail. Metin Aydogdu [10] studied on Free Vibrations of Anti symmetric Angle-Ply Laminated Thin Square Composite Plates and the Ritz method is applied to solve the problems. The present investigation intends to apply threedimensional finite element techniques for the free vibration analysis of thick skew laminates with circular cutout.

\section{PROBLEM DESCRIPTION}

\section{A. Geometric modeling}

The geometry of the problem is shown in Fig. 1. The sides of the plate ' $l$ ' and ' $b$ ' are taken equal to $2 \mathrm{~m}$ and the height of the plate is divided in to four layers of equal thickness $(h / 4)$, Where ' $h$ ' is the total thickness of the laminate. The skew angle $(\alpha)$ is taken as $30^{\circ}$. The circular hole is placed at the geometric centre of the plate. The diameter of the hole is taken as per the $\mathrm{d} / \mathrm{l}$ ratio of 0.3 , the length-tothickness ratio is taken 10 .

\section{B. Finite element modeling}

The element used for the present analysis is SOLID 95 of ANSYS, which is developed, based on three-dimensional elasticity theory and is defined by 20 nodes having three degrees of freedom at each node, translation in the node $\mathrm{x}, \mathrm{y}$ and $\mathrm{z}$ directions. The model with finite element mesh is shown in Fig. 2.

\section{Boundary conditions}

The sides of the skew laminate considered for the present analysis are clamped that is, all the three degrees of freedom of the nodes along the four sides of the skew plate are constrained. 


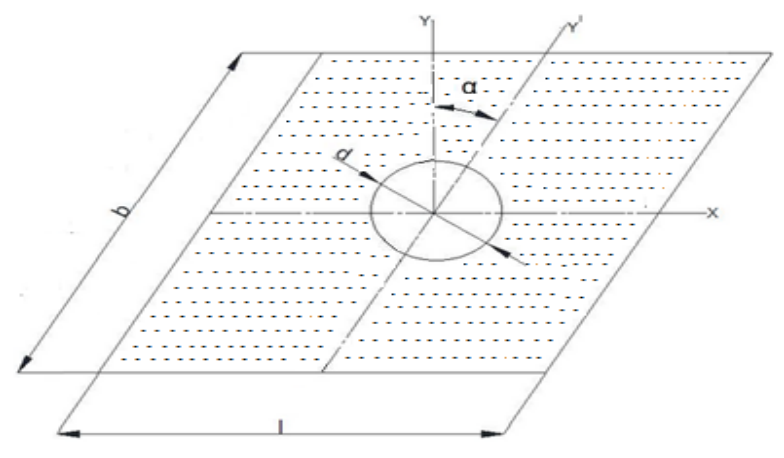

Fig.1 Skew plate with cutout

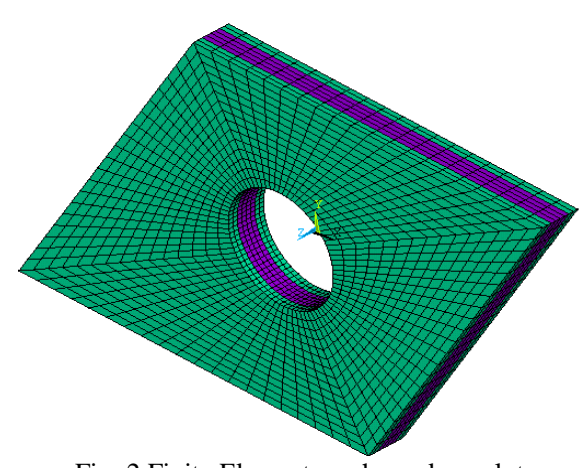

Fig. 2 Finite Element mesh on skew plate

\section{Validation of finite element model (FEM)}

The 3-D FEM is validated with the results available in the literature and found good agreement as shown in Table I.

TABLE I VALIDATION OF THE FINITE ELEMENT RESULTS USING THE 3-D ELASTICITY THEORY FOR $\Omega_{\mathrm{C}}, \Omega_{\mathrm{D}}$

\begin{tabular}{|l|l|l|}
\hline Thickness ratio $(\mathrm{a} / \mathrm{h})$ & $\mathrm{a} / \mathrm{h}=5$ & $\mathrm{a} / \mathrm{h}=5$ \\
\hline Sliding pin supported edge $\left(\mathrm{S}_{2}\right)$ & {$[0 / 90 \ldots .]_{6}^{\mathrm{i}}$} & {$[45 /-45]^{\mathrm{ii}}$} \\
\hline Present $(3-D$ FEM) & 3.4088 & 8.5707 \\
\hline Chao [5] & 3.3495 & 8.2872 \\
\hline Noor [1] & 3.4250 & --- \\
\hline
\end{tabular}

Where the normalized frequency, $\Omega_{\mathrm{c}}=10 \omega \mathrm{h}\left(\rho_{\mathrm{m}} / \mathrm{E}_{2}\right)^{1 / 2}$ and $\Omega_{\mathrm{d}}=\omega \mathrm{a}^{2}\left(\rho_{\mathrm{m}} / \mathrm{E}_{2} \mathrm{~h}^{2}\right)^{1 / 2}$

\section{INFLUENCE OF HYBRID ARRANGEMENT IN SPECIALLY ORTHOTROPIC LAMINATE}

The variation of first five natural frequencies with respect to hybrid laminate arrangements in specially orthotropic laminate is shown in Fig.s 3 to 8 . The different arrangements of hybrid laminates considered are $1 / 2 / 1 / 2,1 / 2 / 2 / 1,2 / 1 / 2 / 1,2 / 1 / 1 / 2,1 / 3 / 1 / 3,1 / 3 / 3 / 1$, $3 / 1 / 3 / 1,3 / 1 / 1 / 3$. The first material laminate is taken as carbon/epoxy (1), the second material laminate is taken as kevlar49/epoxy (2) and the third material laminate is taken as E-Glass/ Epoxy (3). For this hybrid laminate arrangements, the different lamination schemes are taken $0 / 0 / 0 / 0,0 / 90 / 90 / 0$ and 90/90/90/90. In all the cases, the variation of natural frequency increases with respect to increase in the mode number.

For unidirectional cases: From the Fig. 3, the minimum and maximum natural frequencies are obtained at 2/1/1/2 hybrid laminate. There is no significant variation takes place in $(0 / 0 / 0 / 0)$ lamination scheme. From the Fig. 5, the minimum frequency is observed at $1 / 2 / 2 / 1$ and maximum frequency is observed at $2 / 1 / 1 / 2$ hybrid laminates. The reinforcement is better in (90/90/90/90) lamination scheme when compared to $(0 / 0 / 0 / 0)$ laminate. The minimum and maximum natural frequencies of these hybrid arrangements are obtained, because of position of laminas. It states that, the resulting stiffness matrix is increasing for a hybrid laminate of $2 / 1 / 1 / 2$ which in turn increasing the natural frequency. Similarly from the Fig.s 6 and 8, the minimum frequency is observed at 3/1/1/3 and maximum frequency is observed at $1 / 3 / 3 / 1$ hybrid laminates. It states that, the resulting stiffness matrix is increasing for a hybrid laminate of $1 / 3 / 3 / 1$ which in turn increasing the natural frequency. For cross-ply cases: From the Fig. 4, the minimum frequency is observed at $1 / 2 / 2 / 1$ and maximum frequency observed at $2 / 1 / 1 / 2$ hybrid laminates. The minimum and maximum natural frequencies of these hybrid arrangements are obtained, because of position of laminas. It states that, the resulting stiffness matrix is increasing for a hybrid laminate of $2 / 1 / 1 / 2$ which in turn increasing the natural frequency. Similarly from the Fig. 7, the minimum and maximum natural frequencies are obtained at $3 / 1 / 1 / 3$ hybrid laminate. It states that, the resulting stiffness matrix is increasing for a hybrid laminate of $3 / 1 / 1 / 3$ which in turn increasing the natural frequency.

\section{E.Material properties}

Three different types of orthotropic materials namely (1) Carbon/Epoxy, (2) Kevlar49/Epoxy and (3) E-Glass/Epoxy are used for the analysis.

These three material properties Ramakrishna [3] and Isaac [9] are provided in Table II. 
International Journal of Engineering Trends and Technology (IJETT) - Volume 20 Number 1 - Feb 2015

TABLE II MATERIAL PROPERTIES OF KEVLAR49/EPOXY AND E-GLASS/EPOXY

\begin{tabular}{|l|c|c|c|}
\hline Property & Carbon/Epoxy(1) & Kelar49/Epoxy (2) & E-Glass/ Epoxy (3) \\
\hline Young's modulus in x-direction, $\mathrm{E}_{\mathrm{x}}\{\mathrm{GPa}\}$ & 175 & 80 & 41 \\
\hline Young's modulus in y-direction, $\mathrm{E}_{\mathrm{y}}\{\mathrm{GPa}\}$ & 7 & 5.5 & 10.4 \\
\hline Young's modulus in z-direction, $\mathrm{E}_{\mathrm{z}}\{\mathrm{GPa}\}$ & 7 & 5.5 & 10.4 \\
\hline Shear modulus in xy plane, $\mathrm{G}_{\mathrm{xy}}\{\mathrm{GPa}\}$ & 3.5 & 2.2 & 4.3 \\
\hline Shear modulus in yz plane, $\mathrm{G}_{\mathrm{yz}}\{\mathrm{GPa}\}$ & 1.4 & 1.8 & 3.5 \\
\hline Shear modulus in zx plane, $\mathrm{G}_{\mathrm{zx}}\{\mathrm{GPa}\}$ & 3.5 & 2.2 & 4.3 \\
\hline Poisson's ratio in xy plane, $v_{\mathrm{xy}}$ & 0.25 & 0.34 & 0.28 \\
\hline Poisson's ratio in yz plane, $v_{\mathrm{yz}}$ & 0.25 & 0.40 & 0.5 \\
\hline Poisson's ratio in $\mathrm{zx}$ plane, $\mathrm{v}_{\mathrm{zx}}$ & 0.25 & 0.34 & 0.28 \\
\hline Mass density, $\left.\rho \mathrm{Kg} / \mathrm{m}^{3}\right\}$ & 1600 & 1400 & 1970 \\
\hline
\end{tabular}

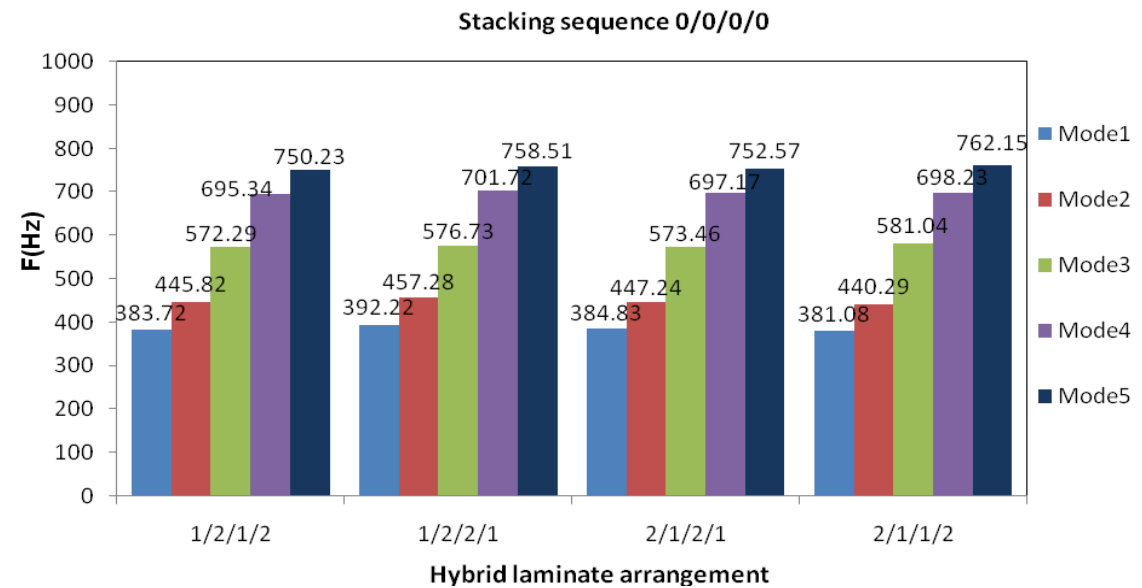

Fig. 3 Variation of frequecy with respect to hybrid laminate arrangements (1/2) for a sequence of 0/0/0/0

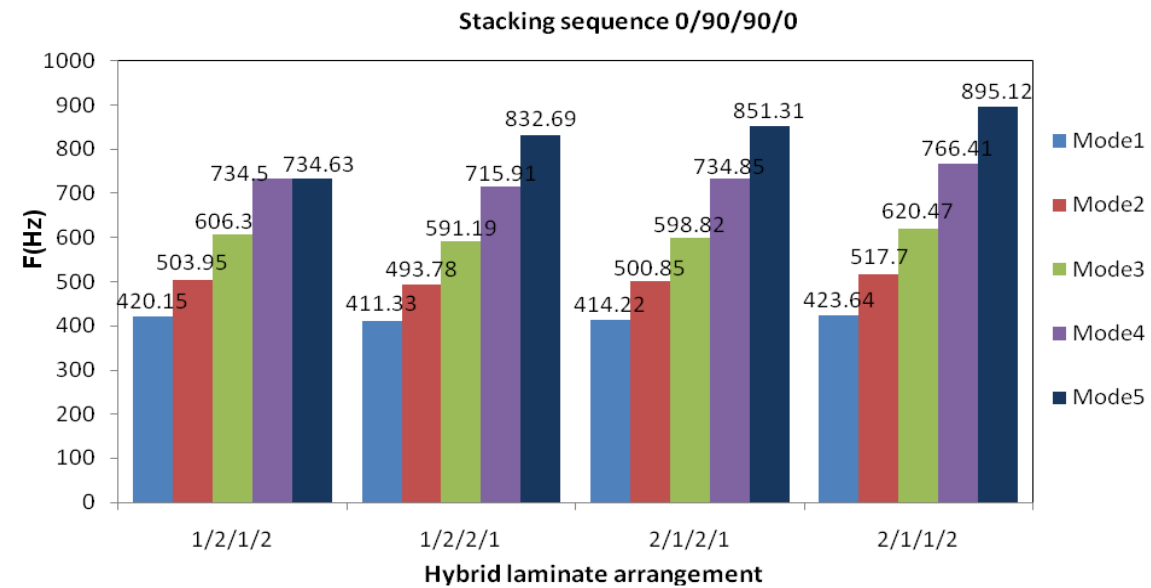

Fig. 4 Variation of frequecy with respect to hybrid laminate arrangements (1/2) for a sequence of 0/90/90/0 


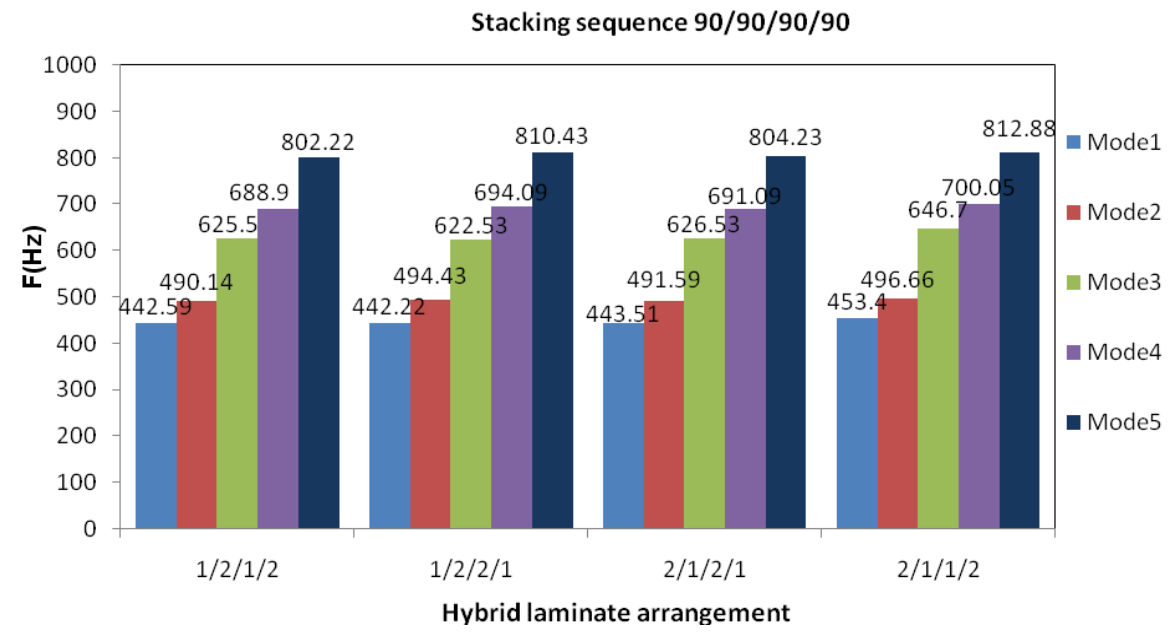

Fig. 5 Variation of frequecy with respect to hybrid laminates (1/2) for a sequence of 90/90/90/90

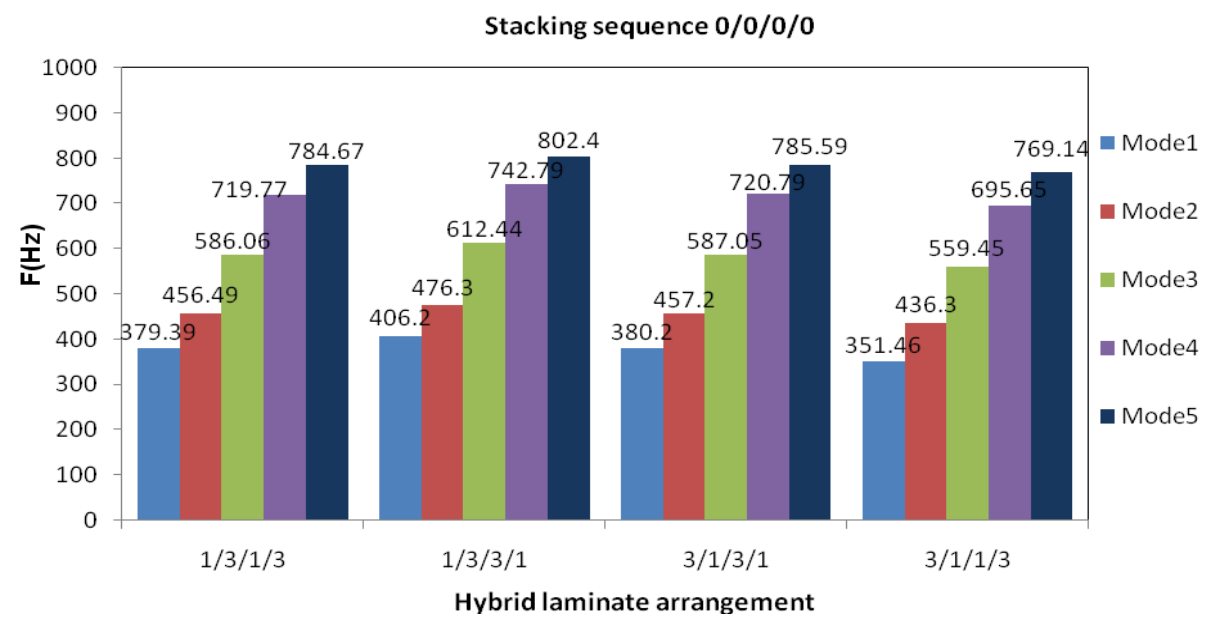

Fig. 6 Variation of frequecy with respect to hybrid laminates (1/3) for a sequence of 0/0/0/0

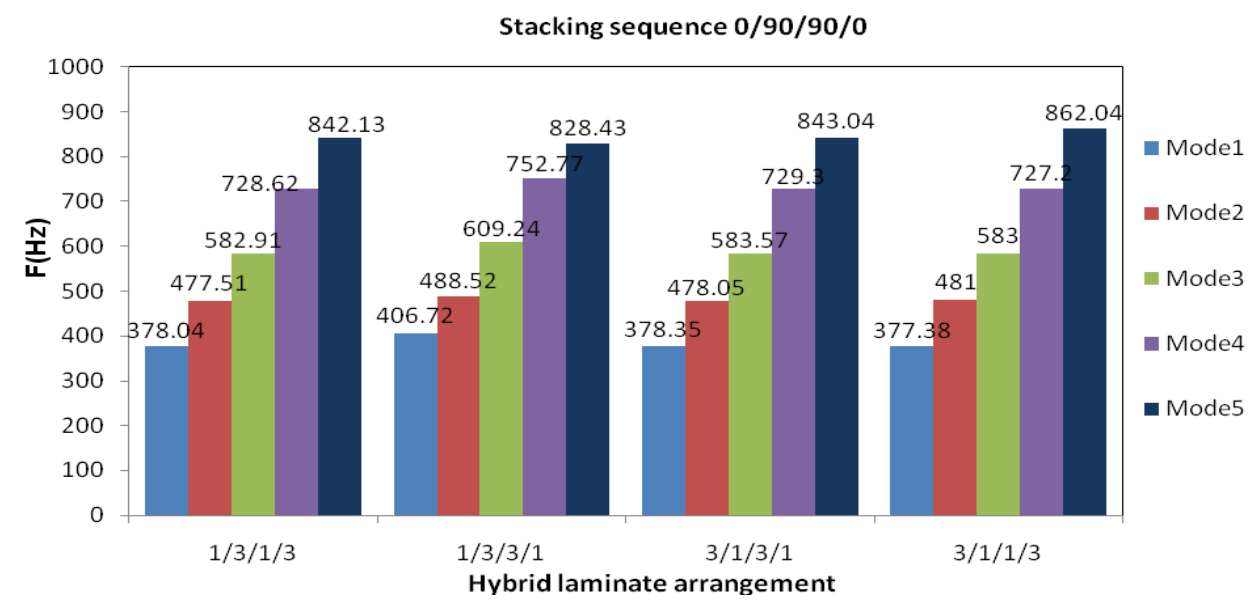

Fig. 7 Variation of frequecy with respect to hybrid laminates (1/3) for a sequence of 0/90/90/0 


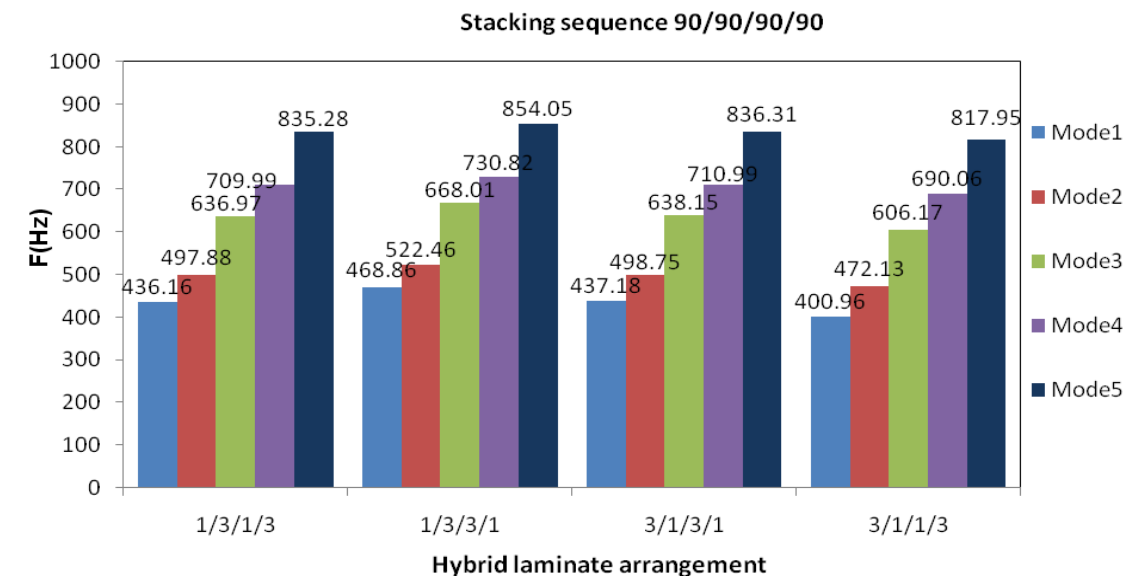

Fig. 8 Variation of frequecy with respect to hybrid laminates (1/3) for a sequence of 90/90/90/90

\section{CONCLUSION}

The influence of hybrid materials of specially orthotropic nature in free vibration analysis of a thick four-layered Fiber Reinforced Plastic skew laminated composite plate with a circular cutout and clamped boundary conditions has been taken up in the present work. From the effect of various hybrid material arrangements, for unidirectional cases, the maximum frequency is high for a hybrid arrangement of $1 / 3 / 3 / 1$ at a lamination scheme of $(90 / 90 / 90 / 90)$ and for cross-ply cases, the natural frequency is high at $2 / 1 / 1 / 2$ hybrid laminate. The present analysis is useful for the design of skew plates with cutouts for dynamic response.

\section{REFERENCES}

[1] A. K. Noor, Free vibrations of multi layered composite plates, AIAA J. 11 , 1973, 1038-1039.

[2] T. Kant, Mallikarjuna, Vibrations of Unsymmetrically Laminated Plates Analyzed by Using A Higher Order Theory with a $C^{o}$ Finite Element Formulation, J. of Sound \& Vib.134, 1989, 116.

[3] S. Ramakrishna, K. M. Rao, N. S. Rao, Dynamic analysis of laminates with elliptical cutouts using the hybrid-stress finite element, 47, 1993, 281-287.
[4] Yook-Kong Yongt, Young Cho, Higher-order, partial hybrid stress, finite element formulation for laminated plate and shell analyses, Comput. Struct.57, 1994, 817-827.

[5] C.C.Chao, Yeong-Chyuan C, Comparison of natural frequencies of laminates by 3-d theory, part I: Rectangular plates, J. Sound Vib. 230, 2000, 985-1007.

[6] Chun-Sheng Chen, Investigation on the Vibration and Stability of Hybrid Composite Plates, J. Reinforced Plast. Comp. 24, 2005, 1747-1758.

[7] Metuin Aydogdu, Free Vibration Analysis of Angle-ply Laminated Beams with General Boundary Conditions, J. Reinforced Plast. Comp. 25, 2006, 1571-1583.

[8] S.A.Mutasher, B.B. Sahari, A.M.S. Hamouda, S. M. Sapuan, Static and dynamic characteristics of a hybrid aluminium /composite drive shaft, Materials design and appl. 221, 2006, 63-76.

[9] Isaac M. Daniel, Ori Ishai, Engineering Mechanics of Composite Materials, Second Edition, 2006.

[10] Metin Aydogdu, Taner Timarci, Free Vibrations of Antisymmetric Angle-Ply Laminated Thin Square Composite Plates, Turkish J. Eng. Env. Sci. 31, 2007, 243-249. 